\title{
Terapi Dzikir Jahar Mengurangi Kecemasan Pada Ibu Pre Operasi Sectio Caecarea
}

\author{
Arisda Candra Satriyawati ${ }^{1}$, Syaifurrahman Hidayat ${ }^{2}$, Yulia Wardita ${ }^{3}$, Nor Arifah ${ }^{4}$ \\ 1,2,3,4 Fakultas Ilmu Kesehatan Universitas Wiraraja \\ dayat.fik@wiraraja.ac.id* \\ *Corresponding author
}

\begin{tabular}{ll}
\hline Informasi artikel & ABSTRAK \\
\hline Sejarah artikel: & Ansietas merupakan satu respon yang dihadapi pasien pre operasi sectio \\
Received: 12-04-2021 & sesarea (SC) sehingga memerlukan penanganan, salah satu terapi non \\
Revised: 24-05-2021 & farmakologis dengan dzikir Jahar. Penelitian ini bertujuan untuk \\
Accepted: 29-05-2021 & menjelaskan pengaruh terapi dzikir jahar terhadap penurunan tingkat \\
\hline Kata kunci: & kecemasan ibu pre-operasi SC. Metode penelitian menggunakan Quasy \\
Terapi Dzikir, kecemasan, & Experiment dengan Pre-Post Test With Control Group Design. Penentuan \\
section caearea & responden dilakukan secara total sampling yaitu ibu hamil pre SC bulan \\
& Maret-Juni tahun 2019 di RSI Garam Kalianget (n=24). Uji statistik \\
& menggunakan Paired T Test, Wilcoxon Test dan Independent T Test. Hasil \\
& uji Paired T Test ada perbedaan tingkat kecemasan pasien pre SC \\
& sebelum dan sesudah diberikan terapi dzikir jahar pada kelompok \\
& intervensi (p = 0,000), terjadi penurunan rata-rata sebesar 9,917. Hasil \\
& uji Wilcoxon tidak ada perbedaan (perubahan) tingkat kecemasan pasien \\
& pre SC sebelum dan sesudah diberikan komunikasi terapeutik pada \\
& kelompok kontrol nilai (p = 0,636), penurunan yang terjadi yaitu 0,83. \\
& Hasil uji Independent T Test tidak ada perbedaan tingkat kecemasan \\
& pasien pre SC sebelum dan sesudah diberikan perlakuan pada kelompok \\
& intervensi dan kelompok kontrol ( p = 0,211). Ada pengaruh pemberian \\
& terapi dzikir jahar terhadap penurunan tingkat kecemasan ibu pre \\
& operasi SC.
\end{tabular}

\section{Key word:}

Dhikr therapy, anxiety, sectio caesarea

\begin{abstract}
Dhikr Jahar Therapy Reduces Anxiety in Pre-Operative Sectio Caesarea Mothers. Mothers often experience anxiety before cesarean section surgery. Non-pharmacological therapy with dhikr Jahar can be a complementary therapy option to reduce anxiety. This study aimed to explain the effect of dhikr therapy on reducing maternal anxiety levels before SC surgery. The research method uses Quasy Experiment with PrePost Test With Control Group Design. The respondents' determination was carried out by total sampling, namely pre-cesarean section surgery pregnant women in March-June 2019 at Garam Islamic Hospital, Kalianget $(\mathrm{n}=24)$. Statistical test using Paired T-Test, Wilcoxon Test, and Independent T-Test. The results of the Paired T-Test showed that there were differences in the level of anxiety of patients before SC before and before being given dhikr therapy in the intervention group $(p=0.000)$; there was an average decrease of 9.917. The Wilcoxon test results showed no difference (change) in the level of anxiety of patients before and before being given therapeutic communication in the control group the value $(\mathrm{p}=0.636)$; the decrease that occurred was 0.83 . In the Independent $\mathrm{T}$-Test results, there was no difference in the level of anxiety before SC before and before being given treatment in the intervention group and the control group $(\mathrm{p}=0.211)$. There is an effect of providing dhikr Jahar therapy to reduce maternal anxiety levels before SC surgery.
\end{abstract}




\section{PENDAHULUAN}

Kejadian Persalinan dengan sesar cukup meningkat sebanyak 10\%-15\% yang direkomendasikan World Health Organization (WHO) dalam meningkatkan kesehatan ibu bayi. Amerika Latin dan wilayah Karibia persalinan sesar mencapai 40,5 persen, diikuti oleh Eropa (25\%), Asia $(19,2 \%)$ dan Afrika (7,3\%). Di Indonesia berdasrkan Riskesdas 2018 menunjukkan prevalensi tindakan sesar sebanyak 17,6 persen, tertinggi di wilayah DKI Jakarta $(31,3 \%)$ dan terendah di Papua $(6,7 \%)$. Data Riskesdas 2013 di Jatim pada tahun 2011 berjumlah 3.401 operasi dari 170.000 persalinan, sekitar 20\% dari seluruh persalinan (Dinkes Provinsi Jawa timur, 2012). Menurut data Dinas Kesehatan Kabupaten Sumenep tahun 2018 menunjukkan kelahiran bedah SC di Kabupaten sumenep mencapai 30\% dari seluruh persalinan. (Dinkes Kebupaten Sumenep, 2019)

Persalinan menggudakan tindakan Caesar berpotensi terhadap stressor yang pada ibu hamil pre operasi sectio caesarea (SC) sehingga mengalami kecemasan. Dimana cemas akan menyebabkan kondisi buruk pada pasien saat operasi, sehingga memperlambat penyembuhan (Ismail, 2014). Salah satu langkah non-farmakologi yang mungkin digunakan untuk mengurangi kecemasan secara spiritual atau intervensi agama (Dzikir), atau Dzikir kepada Allah SWT, adalah kata-kata pujian dan kemuliaan bagi Allah, itu bisa dibacakan dengan lantang atau dalam diam untuk menghasilkan kondisi pikiran yang damai (Nurlia , e t al., 2019).

Penggunaan terapi dzikir jahar dapat digunakan sebagai salah satu intervensi bidan dalam penanganan kecemasan pasien pre operasi SC. Pasien yang mendapatkan terapi dzikir jahar diharapkan dapat meminimalisir rasa nyeri, perasaan cemas, dan memberikan ketenangan jiwa. Ditinjau dari manfaat yang dapat dirasakan dari terapi dzikir jahar, maka peneliti berinisiatif untuk melakukan penelitian "Pengaruh Terapi Dzikir Jahar Terhadap Penurunan Tingkat Kecemasan pada Ibu Hamil Pre
Operasai SC di RSI Garam Kalianget Tahun 2019".

\section{METODE PENELITIAN}

Penelitian ini dilakukan di RSI Garam Kalianget, menggunakan Quasy Experiment dengan desain Pre-Post Test Design With Control Group. Sampel sebanyak 24 orang ibu hamil dari bulan Maret-Juni tahun 2019 dengan teknik total sampling. Analisis data menggunakan Paired T Test, Wilcoxon Test Dan Independent $T$ Test.

\section{HASIL DAN PEMBAHASAN}

Analisis Univariat

Tabel 1 Deskripsi Tingkat Kecemasan Pasien Pre SC Sebelum perlakuan

\begin{tabular}{ccccc}
$\begin{array}{c}\text { Kelomp } \\
\text { ok }\end{array}$ & $\begin{array}{c}\text { Mea } \\
\mathbf{n}\end{array}$ & $\begin{array}{c}\text { Medi } \\
\text { an }\end{array}$ & $\begin{array}{c}\text { Stand } \\
\text { ar } \\
\text { Devia } \\
\text { si }\end{array}$ & $\begin{array}{c}\text { Minimu } \\
\mathbf{m}- \\
\text { Maksim } \\
\text { um }\end{array}$ \\
\hline $\begin{array}{c}\text { Interve } \\
\text { nsi }\end{array}$ & $\begin{array}{c}21, \\
75\end{array}$ & 21,00 & 5,345 & $10-31$ \\
Kontrol & $\begin{array}{c}14, \\
\text { 14 }\end{array}$ & 15,50 & 3,655 & $6-17$ \\
& 5 & & & \\
\hline
\end{tabular}

Tabel 1 menunjukkan kelompok intervensi memiliki nilai mean lebih tinggi dari pada kelompok kontrol sebelum diberikan perlakuan. tingkat kecemasan terendah pada kelompok intervensi sebanyak 10 dan tertinggi sebanyak 31 ,

Pada kelompok intervensi dan kelompok kontrol semua mengalami kecemasan pada saat pe SC. Hal ini dapat terjadi karena ada pencetus ansietas yaitu tindakan SC. Hal ini sesuai dengan pendapat Pieter, Janiwari dan Saragih (2011) yang menyebutkan bahwa ada 2 kategori pencetus ansietas yaitu ancaman terhadap integritas diri dan ancaman terhadap sistem diri. Kecemasan muncul ketika orang menghadapi bahaya atau stressor (Mulyadi, E. \& Hidayat, S. 2014). Tindakan SC dianggap sebagai ancaman integritas diri karena menyebabkan pasien mengalami ketidakmampuan secara fisiologis dalam aktivitas sehari-hari ketika sebelum dan setelah SC. Sebelum SC pasien akan melakukan puasa sebagai pesiapan pre SC, menjalani prosedur pemasangan infus dan 
kateter yang menyebabkan rasa sakit dan tidak nyaman.

Selain itu menurut Laria, ada faktor psikosomatik sebagai faktor predisposisi yang mempengaruhi kecemasan. Seorang pasien pre SC akan mangalami gangguan psikosomatik karena akan menjalani pembedahan pada tubuhnya, pasien akan berpikir apakah ia mampu untuk menjalani hal tersebut, apakah dia akan selamat, apakah bayi yang dilahirkan akan selamat dan sehat, apakah dia akan pulih dengan cepat setelah SC. Hal-hal tersebut membuat pasien diserang kecemasan, walaupun tiap orang berbeda-beda dalam menghadapi SC, namun semua pasein akan mengalami kecemasan dengan berbagai tingakatan.

Tabel 2 Deskripsi Tingkat Kecemasan Pasien Post SC Sesudah Pemberian Perlakuan

\begin{tabular}{ccccc}
\hline Kelompok & Mean & Median & $\begin{array}{c}\text { Standar } \\
\text { Deviasi }\end{array}$ & $\begin{array}{c}\text { Minimum- } \\
\text { Maksimum }\end{array}$ \\
\hline Intervensi & 11,83 & 21,00 & 4,019 & $4-19$ \\
Kontrol & 13,75 & 14,50 & 3,223 & $6-17$ \\
\hline
\end{tabular}

Tabel 2 menunjukkan pada Kelompok kontrol memiliki nilai mean lebih tinggi dari pada kelompok intervensi. Tingkat kecemasan terendah dari kelompok intervensi sebanyak 4 dan tertinggi sebanyak 19.

Hasil penelitian pada tabel 2 menunjukkan nilai mean pada kelompok intervensi lebih rendah dibandingkan kelompok kontrol. Artinya penurunan kecemasan pada kelompok yang diberikan terapi zikir jahar lebih besar dibanding kelompok kotrol dengan perlakuan komunikasi teraputik. Sugesti dan dzikir dapat mempengaruhi kondisi individu, dimana hal tersebut akan memberikan merasa lebih mudah untuk relaksasi (Hidayat, S. dan E. D. M. 2018).

Hal ini dapat terjadi karena zikir adalah salah satu cara mengingat Tuhan, cara untuk berserah diri sehingga pasien bisa mempunyai kepasrahan yang berakibat pada penurunan tingkat kecemasan. Spiritual yang baik apabila dimiliki individu dapat dijadikan sebagai upaya hubungan baik dengan sang pencipta serta antar sesame sehingga dapat menyadari dan mengetahui mengenai tujuan hidup (Hannan M, Hidayat S. 2020; Hidayat, S., Hannan, M., \& Mulyadi, E. (2019). Menurut Purwanto, dzikir kepada sang pencipta tidak hanya dengan kata-kata dan pujian akan tetapi sebuah keyakinan yang diyakini oleh seseorang akan adanya sang pencipta, serta memiliki keimanan yang kuat hanya kepadan Tuhan. Sehingga pasien lebih bisa pasrah dan menyandarkan hidupnya kepada Allah. Zikir juga merupakan cara komunikasi pasien kepada Tuhannya.

Terapi zikir dapat dijadikan sebagai intervensi klinis dari relaksasi untuk mengurangi masalah pikologis, kecemasan, dan mengatasi kelelahan (Zuhra,2017). Dzikir sebagai penyembuh dapat bermanfaan beberapa efek fisik dan psikis dan dapat menyeimbangkan kadar serotonin dan neropineprine di dalam tubuh (Hidayat, S, 2014).

Analisis Bivariat

Tabel 3 Perbedaan Tingkat Kecemasan Sebelum dan Sesudah Diberikan perlakuan

\begin{tabular}{ccccc}
\hline $\begin{array}{c}\text { Kelompok } \\
\text { Intervensi }\end{array}$ & Mean & SD & $\begin{array}{c}\Delta \\
\text { Mean }\end{array}$ & $\begin{array}{c}\mathbf{p} \\
\text { Value* }\end{array}$ \\
\hline Sebelum & 21,75 & 5,345 & 9,917 & 0,000 \\
Sesudah & 11,83 & 4,019 & & \\
\hline
\end{tabular}

Hasil uji Paired t Test menunjukkan ada perbedaan tingkat kecemasan pasien pre SC sebelum dan sesudah diberikan terapi dzikir jahar pada kelompok intervensi nilai $\mathrm{p}=0,000>\alpha=0,05$. Dan pada nilai mean dari sebelum melakukan terapi dzikir sebesar 21,75 ke sesudah melakukan terapi dzikir sebesar 11,83 . Terjadi penurunan rata-rata sebesar 9,917.

Berdasarkan data diatas dapat disimpulkan bahwa zikir jahar dapat menurunkan cemas pasa pasien pre SC secara signifikan. Hal ini sesuai dengan pernyataan Zuhra (2017) bahwa melakukan zikir sama nilainya dengam terapi rileksasi (relaxation therapy), yaitu satu bentuk terapi dengan menekankan upaya mengantarkan pasien bagaimana cara ia 
harus beristirahat dan bersantai-santai melalui pengurangan ketegangan atau tekanan psikologis. Banyak dari kalangan psikolog-sufistik memiliki ketenangan dan kedamaian jiwa yang luar biasa.

Terapi zikir jahar dapat diaplikasikan sebagai alternatif terapi non farmakologis untk mengurangi kecemasan pada ibu hamil pre SC, dengan dilakukan terapi tersebut pasien dapat lebih siap secara mental dan fisik dalam menghadapi persalinan sehingga nantinya dalam penyembuhan juga akan berlangsung dengan cepat dan baik.ini berimbas juga pada kemampuan ibu dalam merawat bayinya kelak. Karena ibu tidak cemas maka masa nifas dan masa menyusui akan dapat berjalan dengan baik (salat, 2019). Menurut zuhra (2017) zikir dapat mengembalikan kesadaran seseorang yang hilang, sebab aktivitas zikir mendorong seseorang untuk mengingat, menyebut kembali hal-hal yang tersembunyi dalam hatinya. Zikir juga mampu mengingatkan seseorang bahwa yang membuat dan menyembuhkan penyakit hanyalah Allah Swt semata, sehingga zikir mampu memberi sugesti penyembuhannya.

Tabel 4 Perbedaan Tingkat Kecemasan Pasien Pre SC Sebelum dan Sesudah Diberikan Komunikasi Terapeutik pada Kelompok Kontrol

\begin{tabular}{lcccc}
\hline $\begin{array}{l}\text { Kelompok } \\
\text { kontrol }\end{array}$ & Mean & SD & $\begin{array}{c}\Delta \\
\text { Mean }\end{array}$ & $\begin{array}{c}\text { P } \\
\text { Value* }\end{array}$ \\
\hline Sebelum & 14,58 & 3,655 & & \\
Sesudah & 13,75 & 3,223 & 0,83 & 0,580 \\
\hline
\end{tabular}

SD $=$ Standard Deviasi, $\Delta=$ Penurunan, ${ }^{*}=\mathrm{Uji}$ Paired t Test

Hasil uji Paired t Test di atas diketahui tidak ada perbedaan (perubahan) tingkat kecemasan pasien pre SC sebelum dan sesudah diberikan komunikasi terapeutik pada kelompok kontrol nilai $\mathrm{p}=0,636>\alpha=$ 0,05 . Kemudian dapat dilihat lebih lanjut pada nilai mean dari sebelum diberikan komunikasi terapeutik sebesar 14,58 ke sesudah diberikan komunikasi terapeutik sebesar 13,75 , penurunan yang terjadi tidak signifikan yaitu hanya 0,83 .
Dari data diatas dapat disimpulkan bahwa pemberian komunikasi terapeutik hanya sedikit menurunkan tingkat kecemasan pada ibu pre SC. Hal ini dapat terjadi karena dalam komunikasi terapeutik memerlukan keahlian dan kemampuan khusus, jika terapis tidak memenuhi syarat terapi yang baik dan benar maka keadaan dimana pasien belum melakukan kepasrahan, masih ada ganjalan dalam hati dan pikirannya, apakah sugesti yang diberikan pada saat terapeutik akan benarbenar terjadi, apakah benar dia dan bayinya akan baik-baik saja tanpa komplikasi akan dialami pasien.

Kurang berhasilnya komunikasi terapeutik yang dilakukan dapat terjadi karena kemampuan komunikasi terapeutik peneliti masih kurang baik sehingga relaksasi dan sugesti yang diberikan belum sepenuhnya dapat disampaikan dan diterima dengan baik oleh pasien. Meskipun penurunan tingkat kecemasan pada kelompok kontrol sangat kecil namun sudah mampu menjawab bahwa terapi zikir jahar lebih efektif dalam menurunkan kecemasan pada pasien pre SC.

Tabel 5 Perbedaan Tingkat Kecemasan Pasien Pre SC Sesudah Diberikan Perlakuan pada Kelompok Intervensi dan Kelompok Kontrol

\begin{tabular}{lcccc}
\hline $\begin{array}{c}\text { Kelompok } \\
\text { Responden }\end{array}$ & Mean & SD & Mean & $\begin{array}{c}\mathrm{P} \\
\text { Value }^{* \ldots * * *}\end{array}$ \\
\hline $\begin{array}{l}\text { Kelompok } \\
\text { Intervensi }\end{array}$ & 11,83 & 4,019 & 1,92 & 0,211 \\
$\begin{array}{l}\text { Kelompok } \\
\text { Kontrol }\end{array}$ & 13,75 & 3,223 & & \\
\hline SD Standard deviasi, & & & & \\
\hline
\end{tabular}

SD = Standard deviasi, - = penurunan, ${ }^{*}=\mathrm{uji}$ Independent $t$ Test

Hasil uji Independent $t$ Test di atas diketahui tidak ada perbedaan (perubahan) tingkat kecemasan pasien pre SC sebelum dan sesudah diberikan perlakuan pada kelompok intervensi dan kelompok kontrol dengan nilai $p=0,211>\alpha=0,05$. Kemudian dapat dilihat lebih lanjut pada selisih nilai mean antara kelompok intervensi dan kelompok kontrol hanya sebesar 1,92. Dari data tersebut dapat disimpulkan bahwa kelompok intervensi dan kelompok kontrol sama-sama mengalami penurunan tingkat kecemasan setelah diberikan perlakuan 
walaupun dengan nilai yang berbeda. Namun pernurunan tingkat kecemasan paling tinggi terjadi pada kelompok intervensi, yang artinya terapi zikir jahar mempunyai efektifitas yang lebih baik daripada komunikasi terapeutik. Hal ini dapat terjadi karena kemamuan komunikasi terapeutik tiap orang berbeda-beda, dan pemahaman pasien juga berbeda-beda. Namu pada terapi zikir jahar lebih efektif dikarenakan tidak ada campur tangan pihak ke tiga sebagai mediator terapi. Sehingga kepasrahan pasien kepada Allah dapat terjadi secara alami dan atas kesadaran pasien itu sendiri. Menurut Zainul (2015) zikir juga harus diniatkan dengan sepenuh hati dan keyakinan diri yang kuat sehingga manfaatnya akan maksimal.

\section{KESIMPULAN}

Sebagian besar responden yang mengalami kecemasan sedang pada pre SC sebelum intervensi dzikir jahar. Sebagian besar responden mengalami penurunan kecemasan pada pre SC setelah intervensi dzikir jahar. Terdapat pengaruh yang bermakna antara pemberian terapi dzikir jahar terhadap penurunan tingkat kecemasan ibu hamil pre SC.

\section{DAFTAR PUSTAKA}

Baits, Ai Nur. 2015. Untukmu yang sedang sakit: Doa dan Dzikir Amalan. Yogyakarta: Yufid Publishing

El Mubarok, Manshur. 2014. Lengkap \& praktik doa dzikir harian khusus ibu hamil. Jakarta: Wahyu Qolbu

Hannan M, Hidayat S. (2020). Spiritual Status Related to Life Quality of Elderly. Wiraraja Medika: Jurnal Kesehatan.10(2):6-12

Hidayat, S. (2014). Dzikir Khafi untuk Menurunkan Skala Nyeri Osteoartritis Pada Lansia. Jurnal Ilmu Kesehatan, 1(1), 13-22. https://doi.org/https://doi.org/10. 24929/jik.v1il.119

Hidayat, S., Hannan, M., \& Mulyadi, E. (2019). The Effectiveness of Self-Surrender Exercise and Dzikir Therapy in Improving the Quality of Sleep in A Nursing Home in Pasuruan,

\section{Indonesia Road. International} Journal of Psychosocial Rehabilitation, 24(4), 5188-5197. doi: 10.37200/IJPR/V24I4/PR201617

Hidayat, S. dan E. D. M. (2018). Terapi Kombinasi Sugesti Dan Dzikir Dalam Peningkatan Kualitas Tidur Pasien. Care: Jurnal Ilmiah Ilmu Kesehatan, 6(3), 219-230. Retrieved from https://jurnal.unitri.ac.id/index.php/ care/article/view/953

Mulyadi, E. \& Hidayat, S. (2014). Hubungan mekanisme koping individu dengan kecemasan komunikasi interpersonal pada mahasiswa ners. Jurnal Kesehatan "Wiraraja Medika”, 4(2), 5459.

Nadezul, Hermawan. 2009. Kiat sehat pranikah: Menjadi calon ibu, membesarkan bayi dan membangun keluarga muda. Jakarta: Buku Kompas

Nadezul, Hermawan, 2010. Cantik, cerdas dan feminim: kesehatan perempuan sepanjang masa. Jakarta: Buku Kompas

Nurlia, Y., N., Samsudin, Wanmat, Masdar, Liu, et al. (2019). Listening to Islamic Praises (Dzikir) Is More Effectif In Reducing Perioperative Anxiety Levels When Compared to Nature-Based Sounds In Muslim Patients Undergoing Surgery Under Regional Anesthesia. Journal International IMJM Volume 18 No. 3, Desember 2019. 32.

Pieter, Z. H., \& Lubis, L. N. (2017).Pengantar Psikologi dalam Keperawatan. Jakarta: Kencana divisi dari prenada media group.

Purwanto, S. 2016. Relaksasi dzikir. Fakultas Psikologi Universitas Muhammadiyah Surakarta, SUHUF, Vol. XVIII, No.01/Mei 2012: 39-49

Salat, S. Y. S., \& Suprayitno, E. (2019). HUBUNGAN KECEMASAN IBU MENYUSUI DENGAN KELANCARAN PENGELUARAN AIR SUSU IBU (ASI) DI BPS KERTA TIMUR KECAMATAN DASUK KABUPATEN SUMENEP: Sumenep. Jurnal IImiah Kebidanan (Scientific Journal of Midwifery), 5(2), 5156.

Zaini, M (2019). Asuhan Keperawatan Jiwa Masalah Psikososial. Yogyakarta: Cv Budi Utomo cetakan pertaman 
Zainul, Zen. 2015. Kekuatan metode lafidzi: hidup sehat dengan olah lahir, batin dan fikir. Jakarta: QultumMedia

Zuhra, C. I. (2017, June). Zikir sebagai Psikoterapi. Tribun.com. Retrieved from https://aceh.tribunnews.com/ 2017/06/09/zikir-sebagai psikoterapi 